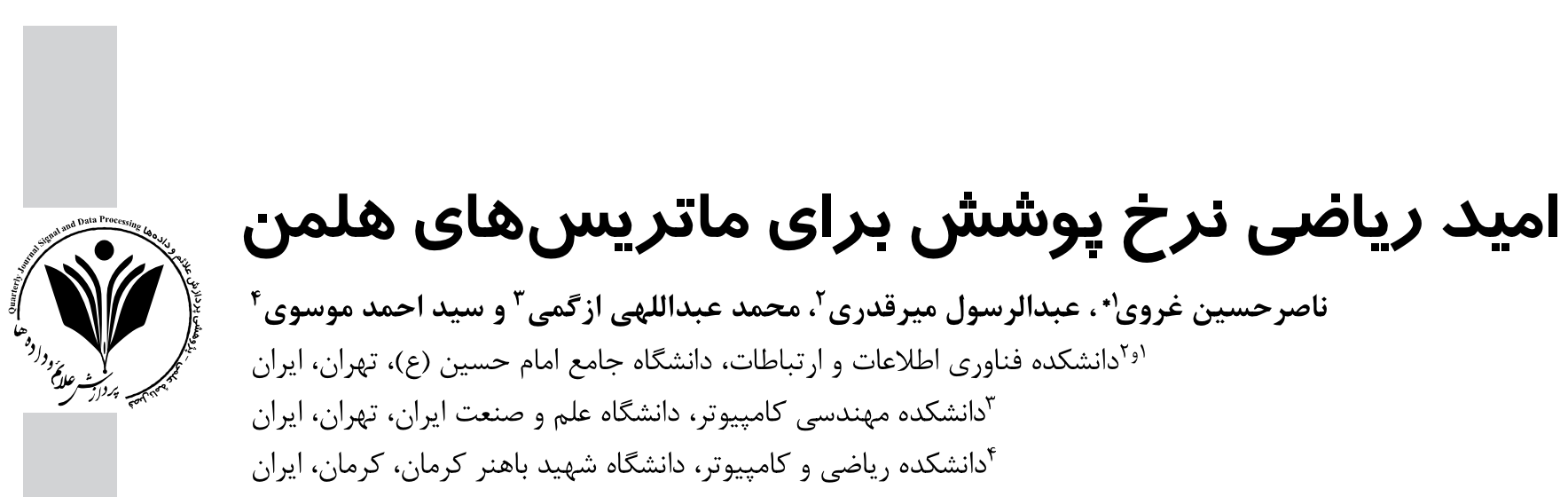

جكيده

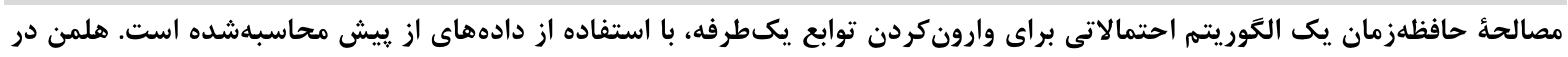

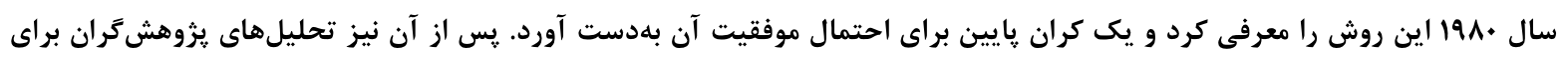

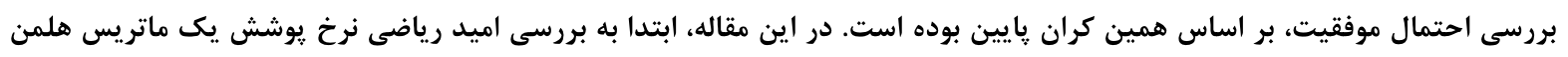

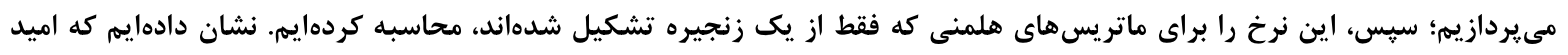

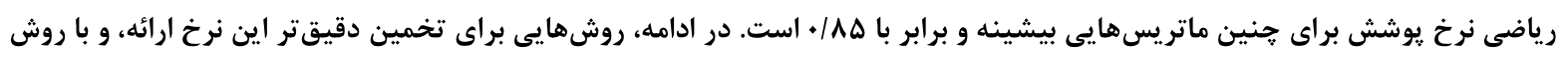

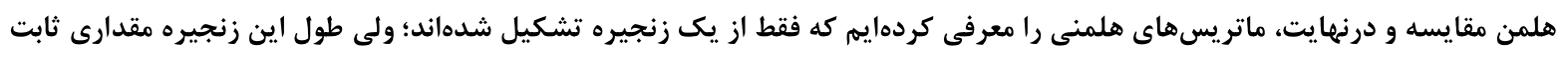

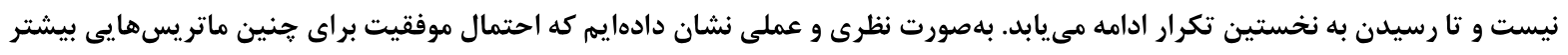
از روش هلمن است. وازٔكان كليدى: مصالحة حافظهزمان، تابع يكطرفه، ماتريس هلمن، اميد رياضى نرخ يوشش

\title{
Expected coverage rate for the Hellman matrices
}

\author{
Nasser Hossein Gharavi*1, Abolrasoul Mirghadri², Mohammad Abdollahi Azgomi ${ }^{3}$ \& \\ Sayyed Ahmad Mousavi ${ }^{4}$ \\ ${ }^{1,2}$ Faculty of Information and Communication Technology, Imam Hossein Comprehensive \\ University, Tehran, Iran. \\ ${ }^{3}$ Faculty of Computer Engineering, Iran University of Science and Technology, Tehran, Iran \\ ${ }^{4}$ Faculty of Mathematics and Computer, Shahid Bahonar University of Kerman, Kerman, Iran
}

\begin{abstract}
Hellman's time-memory trade-off is a probabilistic method for inverting one-way functions, using precomputed data. Hellman introduced this method in 1980 and obtained a lower bound for the success probability of his algorithm. After that, all further analyses of researchers are based on this lower bound. In this paper, we first studied the expected coverage rate (ECR) of the Hellman matrices, which are constructed by a single chain. We showed that the ECR of such matrices is maximum and equal to 0.85 . In this process, we find out that there exists a gap between the Hellman's lower bound and experimental coverage rate of a Hellman matrix. Specifically, this gap is larger, when considering the Hellman matrices constructed with one single chain. So, we are investigated to obtain an accurate formula for the ECR of a Hellman matrix. Subsequently, we presented a new formula that estimate the ECR of a Hellman matrix more accurately than the Hellman's lower bound. We showed that the given formula is closely match experimental data.
\end{abstract}


In the last, we introduced a new method to construct matrices which have much more ECR than Hellman matrices. In fact, each matrix in this new method is constructed with one single chain, which is non-repeating trajectory from a random point. So, this approach result in a number of matrices that each one contains a chain with variable length. The main advantage of this method is that we have more probability of success than Hellman method, however online time and memory requirements are increased. We have also verified theory of this new method with experimental results.

Keywords: time-memory trade-off, one-way function, Hellman matrix, expected coverage rate.

متمايزشدهء [2,3] و جداول رنخين كمانى ^ [14] هستند. براى مطالعهُ بيشتر در اين زمينه مراجع [1, $[1,9,12$ بسيار مفيد هستند.

تاكنون جندين كران تقريبى براى اميد رياضى نرخ

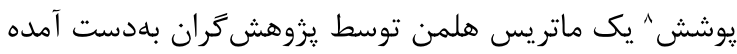

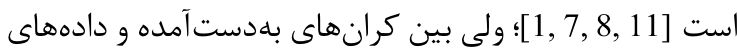
تجربى اختلاف زيادى وجود دارد.

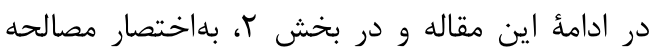

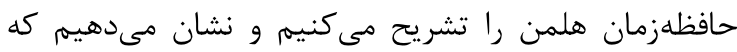

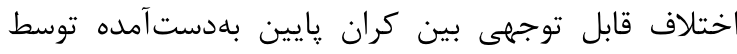

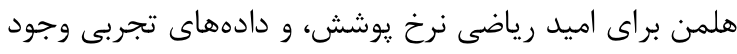

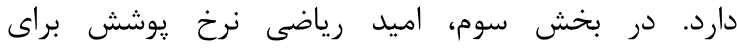

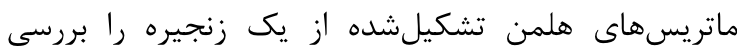

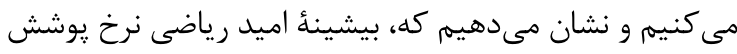

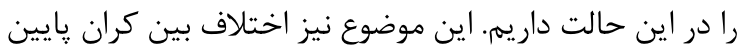
بهدستآمده توسط هلمن و اميد رياضى نرخ يوشش رالت رأ تأييد

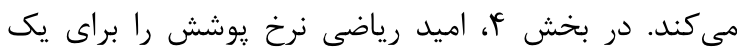

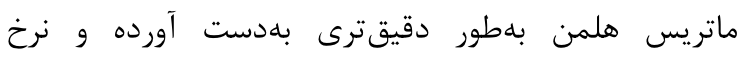

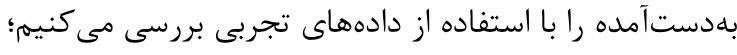

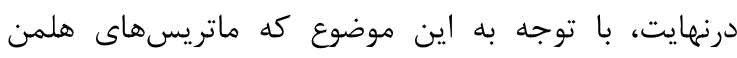

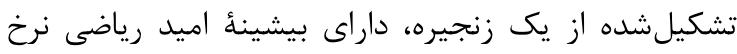

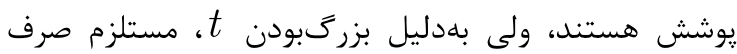

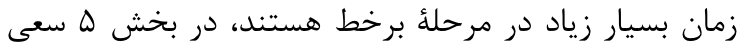

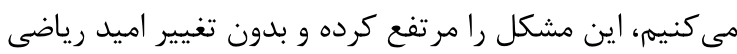

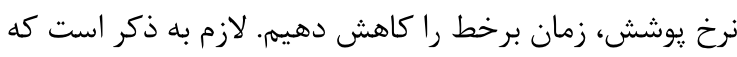

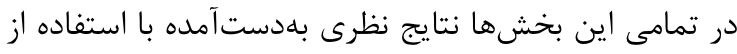
دادههاى تجربى بررسى و تأييد شدهاند.

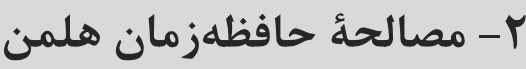

در سرتاسر اين مقاله، براى تحليل احتمالاتى مصالحه حافظهزمان، فرض مى كنيم

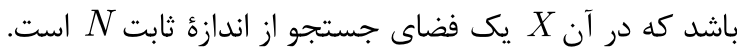

${ }^{6}$ Distinguished points

${ }^{7}$ Rainbow tables

${ }^{8}$ Expected coverage rate (ECR)

\section{- - مقدمه}

توابع يكىرفه' بهطورتقريبى در همه جاى نظريأ رمزنگارى وجود دارند. امنيت برنامههاى رمزشده، سازوكارهاى تعيين

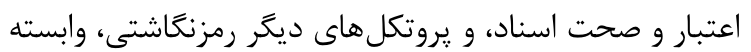
به دشوراى وارونكردن توابع يكطرفه هستند. توابع يكطرفه وفرئ

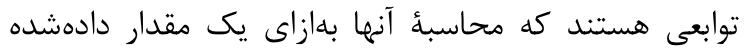

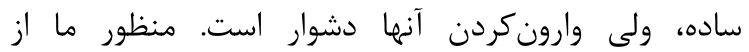

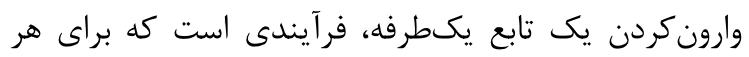

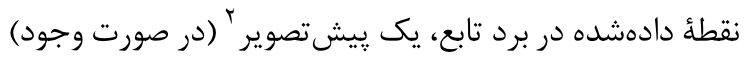

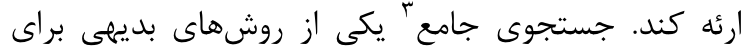

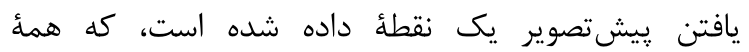

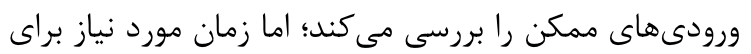

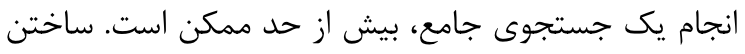

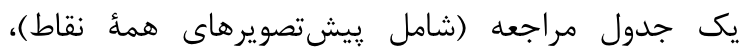
مىتواند راهحل ديگرى باشد. در اين حالت، براى توابعى كه

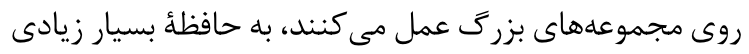

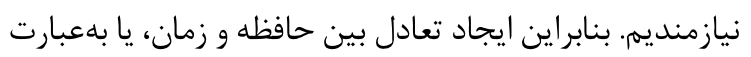

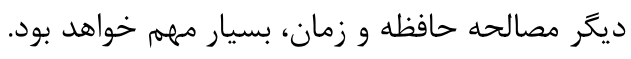

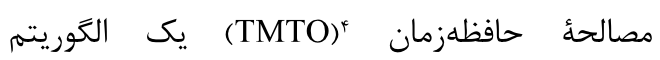
احتمالاتى براى وارون كردن توابع يكطرفه است. نخستين الكوريته TMTO توسط هلمن در سال • • 191 معرفى شده است [7]. اين الكوريتم يك مصالحه بين زمان و حافظه دمانه

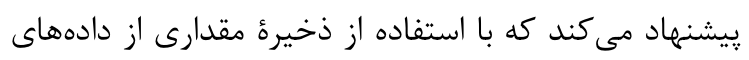
ييشمحاسبهشده در يك حافظه قابل انجام است. TMTO

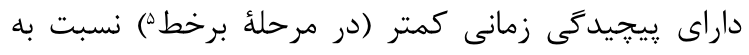

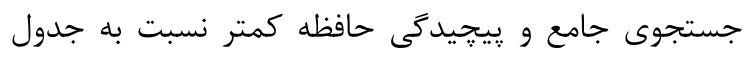
مراجعه است. در ادامه تعميمها و بهبودهاى بسيارى از الخوريتم

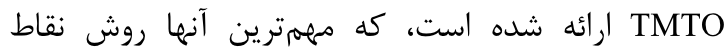

\footnotetext{
${ }^{1}$ One-way functions

${ }^{2}$ Pre-image

${ }^{3}$ Exhaustive search

${ }^{4}$ Time memory trade-off

${ }^{5}$ Online phase
} 
نقاط انتهايى جدول هلمن مطابقت داشته باشد، با استفاده از

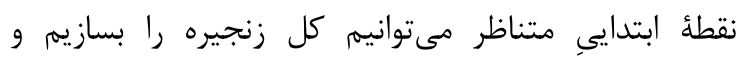

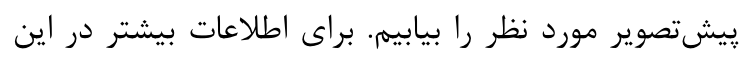

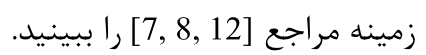

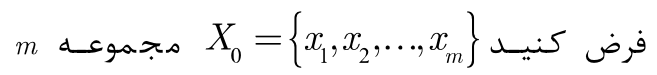
نقطه شروع تصادفى (كه ممكن ا ست، برخى از آنها تكرارى باشند) و و

$X_{j} \equiv f^{j}\left(X_{0}\right) \equiv\left\{f^{j}\left(x_{0}\right), f^{j}\left(x_{1}\right), \ldots, f^{j}\left(x_{m}\right)\right\}$

مجموعه نقاط ستون (j+1) ماتريس هلمن باشد. همجنين

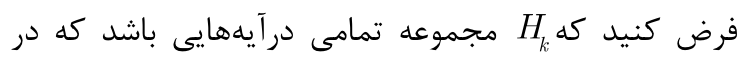

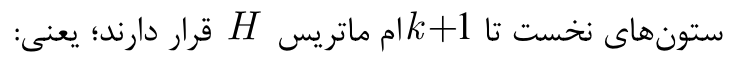
$H_{k}=X_{0} \cup X_{1} \cup \cdots \cup X_{k}$ $=\left\{f^{j}\left(x_{i}\right): 1 \leq i \leq m, 0 \leq j \leq k\right\}$.

متغير تصادفى | $H_{t-1}$

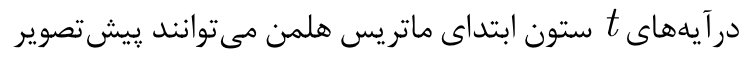

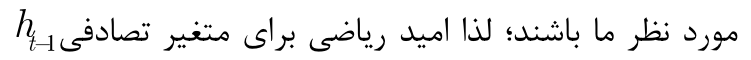
بسيار مهم خواهد بود. توجه كنيد كه، بهدليل تكرارىبودن مئن

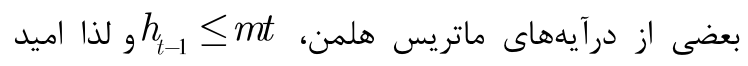

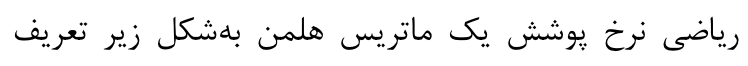

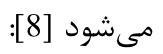

$$
E C R(N, m, t)=\frac{1}{m t} \mathbb{E}\left(h_{t-1}\right),
$$

كه يك اندازه براى محاسبه نرخ يوشش مورد انتظار ما براى

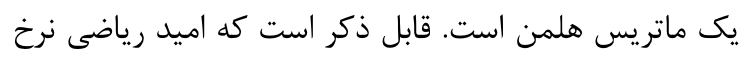
يوشش بلصورت ميانكين مقادير و همل نقاط شروع در مجموعه X

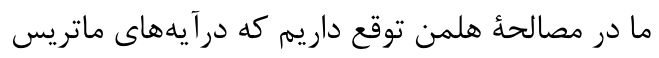

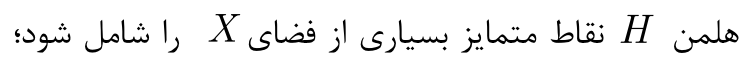

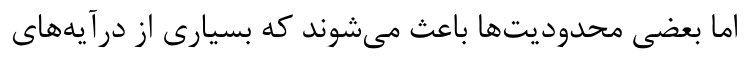
ماتريس هلمن تكرارى باشند. اين مشكلات بهشرح زير هستند: نخست اين كه، ممكن است، يك زنجيره هلمن (يا يك سطر

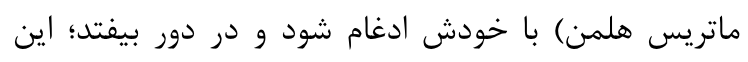

تابع تصادفى، تابعى است كه بلهور يكنواخت و تصادفى از

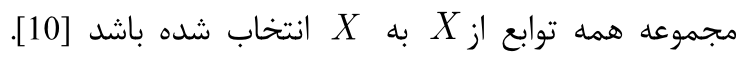

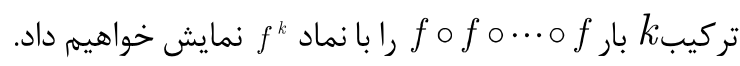
همجنين يك زنجيرة هلمن'، براى نقطة دادهشه

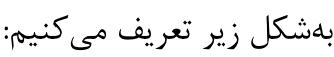
$x, f(x), f^{2}(x), f^{3}(x), \ldots$

فرض كنيد تصوير y در برد تابع f داده شده باشد. هدف الكَوريتم TMTO بهدست آوردن ورودى x در در دامنهُ تابع است؛ بهطورى كه (x) هارامترهاى صحيح و مثبت ماتريس r [7]. اين روش از دو مرحله تشكيل شده است: مرحلئ

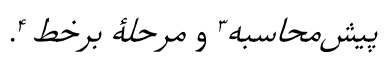

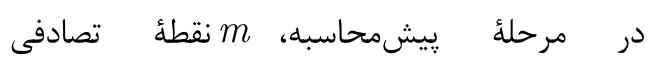
مجمع مجموعه X انتخاب مىشوند. در اين صورت، ماتريس ( هلمن بلشكل زير تعريف مىشود:

$$
H=\left(\begin{array}{ccccc}
x_{1} & f\left(x_{1}\right) & f^{2}\left(x_{1}\right) & \cdots & f^{t}\left(x_{1}\right) \\
x_{2} & f\left(x_{2}\right) & f^{2}\left(x_{2}\right) & \cdots & f^{t}\left(x_{2}\right) \\
\vdots & \vdots & \vdots & \ddots & \vdots \\
x_{m} & f\left(x_{m}\right) & f^{2}\left(x_{m}\right) & \cdots & f^{t}\left(x_{m}\right)
\end{array}\right) .
$$

ستونهاى ابتدا و انتهاى ماتريس هلمن H ر را در كنار

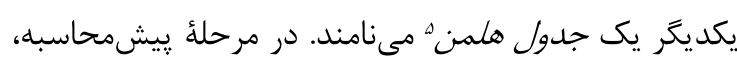

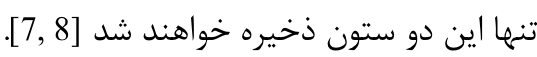

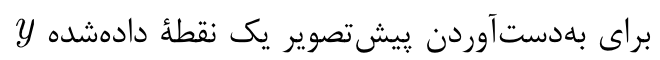

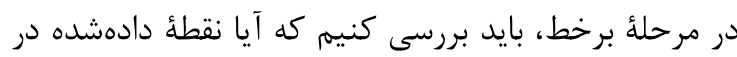

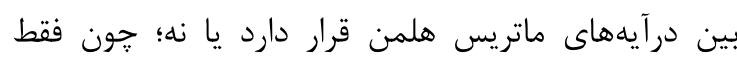

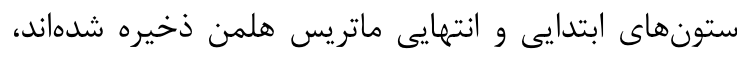
يك زنجيره به شكل ...

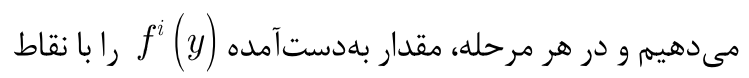
انتهايى جدول هلمن مقايسه مى كنيه. اخر (y)

\footnotetext{
${ }^{1}$ Hellman chain

${ }^{2}$ Matrix stopping rule

${ }^{3}$ Precomputation phase

${ }^{4}$ Online phase

${ }^{5}$ Hellman table
} 
$1-\left(1-\operatorname{ECR}(N, m, t) \cdot \frac{m t}{N}\right)^{r}$.

هنغامى كه C N اين مقدار بهطورتقريبى برابر است با: $1-\mathrm{e}^{-E C R(N, m, t) \frac{m t}{N} r}$.

بنابراين براى محاسبة احتمال موفقيت مصالحه هلمن، كافى

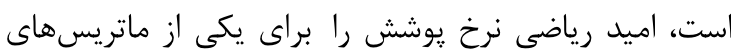

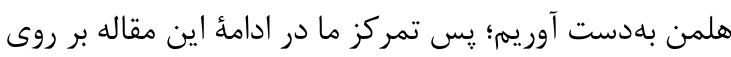
اميد رياضى نرخ بوشش يكى ماتريس هلمن خواهد بود. هلمن در [7]، كران يايين زير را براى اميد رياضى نرخ يوشش يك ماتريس هلمن بلدست در آورد:

$\operatorname{ECR}(N, m, t) \geq \frac{1}{m t} \sum_{i=1}^{m} \sum_{j=1}^{t}\left(1-\frac{i t}{N}\right)^{j}$.

$m t^{2}=N$ هلمن بلهورت عددى تشريح كرد، هنعامى كهى

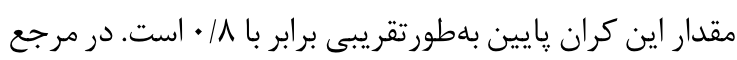
[11]، قسمت سمت راست معادله (ז) با دقت بيشتر محاسبه شد و كران زير در حالت $\operatorname{ECR}(N, m, t) \geq \int_{0}^{1} \frac{1-e^{-x}}{x} \mathrm{~d} x \approx 0.796599$.

فرض كنيد

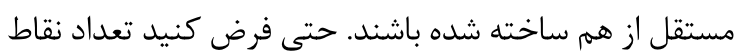
تكرارى در يك ماتريس هلمن بسيار كم باشد؛ يعنى (ECR $(N, m, t) \approx 1$ توقف ماتريس $m t^{2}=N$ و با استفاده از معادله (Y)، احتمال

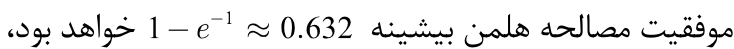

$$
\text { كه احتمال موفقيت خوبى نيست. }
$$

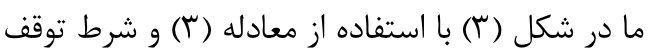

ماتريس

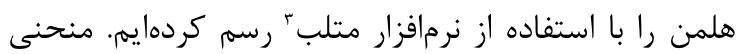
آبىرنى در اين شكل، كران را بر حسب لعاريتم طول زنجيره (يعنى (t) جند در مورد اعتبار اين كران شكى وجود ندارد، اما در ادامه

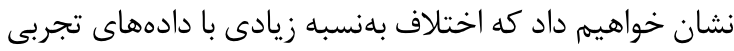

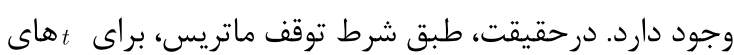
بزرگ و نزديك به شرط نمىشود و بنابراين نمىتوان از اين كران استفاده كرد.
وضعيت زمانى اتفاق مىافتد كه براى $f^{j_{1}}\left(x_{i}\right)=f^{j_{2}}\left(x_{i}\right)$ سطر $i$ ام ماتريس هلمن داشته باشيم (شكل (1) ا ببينيد).

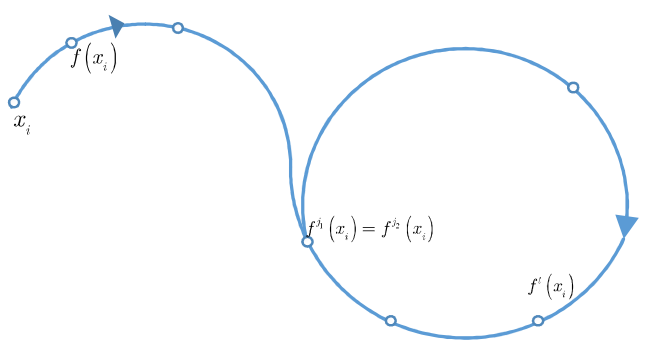

(شكل -1): دور در يكى زنجيره هلمن

(Figure-1): Loop in a Hellman chain

دوم اين كه، ممكن است دو يا جند زنجيره هلمن با يكديكر ادغام شوند. در اين حالت براى دو نقطه شروع متمايز مثل

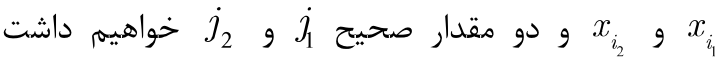
و يعنى در اين مكان برخورد بين $f^{j_{1}}\left(x_{i_{1}}\right)=f^{j_{2}}\left(x_{i_{2}}\right)$ زنجيره اتفاق مىافتد و لذا در ادامه نيز هر دو زنجيره با يكديگر ادغام مىشوند (شكل (r) را ببينيد).

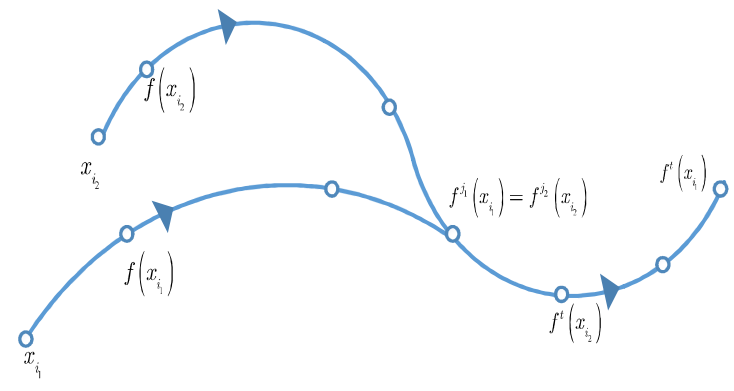

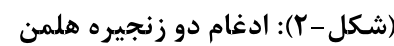

(Figure-2): Merge of two Hellman chain

لذا ييشنهراد شده است كه علاوه بر كاهش تعداد سطرهاى يك ماتريس هلمن، r ماتريس هلمن با استفاده از توابع مركب تئن

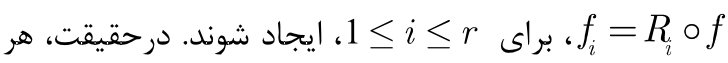
(از ديد $R_{i}: X \rightarrow X$ است، كه آن را يك تابع احيا' مىنامند. بهعنوان مثال، اين تابع

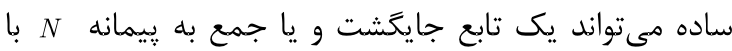

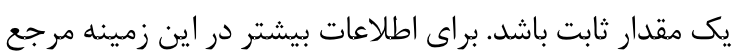

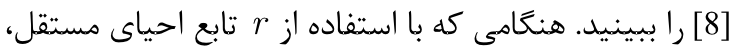
r ماتريس هلمن (t+1) باشيم، احتمال موفقيت` مصالحهٔ هلمن بهشكل زير محاسبه

مىشود [8]:

${ }^{1}$ Reduction function

${ }^{2}$ Success probability 
نظرى و تجربى (بهخصوص در حالت ) مشهود است. از طرف ديكر منحنى تجربى نشان مى دهد كه اميد رياضى نرخ يوشش، صعودى است و براى t هاى بزرى و نزديك به

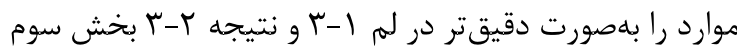
نشان خواهيم داد.

يكى از مشكلات بزرگى كه در مرحله برخط و دو بهعلت

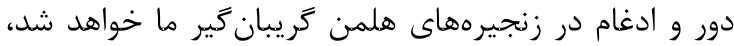

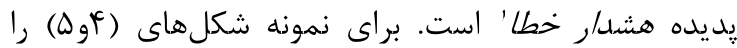
ببينيد. در شكل (f) نقاط انتهايى هر دو زنجيره، يعنى 的 $f^{t}\left(x_{i_{2}}\right) f^{t}\left(x_{i_{1}}\right)$ اين صورت، اگر در مرحله برخط تصوير y y روى زنجيره دوم

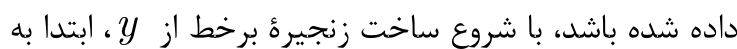
نقطه انتهايى ( $f^{t}\left(x_{i_{1}}\right.$ برخورد مى كنيمى و لذا بهاشتباه نتيجه خواهيم گرفت كه بيشتصوير y دارد. بنابراين با شروع از نقطه $x_{i_{1}}$ مورد نظر برسيم. حالت ديگر هشدار خطا در شكل (ه) نمايش داده شده است. همانطور كه مىبينيد، ممكن است، متناظر

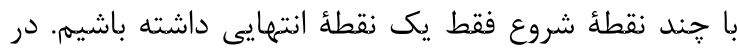
اين وضعيت بايد در مرحلهٔ برخط، جندين زنجيره با استفاده از اين نقاط شروع تشكيل دهيه.

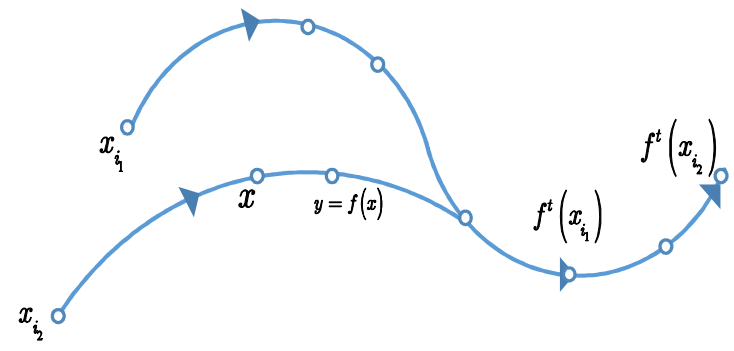

(شكل - (f) : بديده هشدار خطا

(Figure-4): False alarm situation

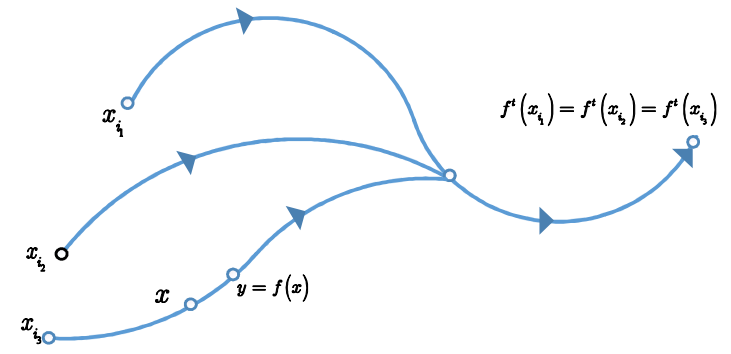

(شكل - (ه): يديده هشدار خطا

(Figure-5): False alarm situation

${ }^{1}$ False alarm
در اين مقاله، براى توليد دادههاى تجربى از الگوريتم

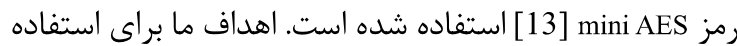
از اين الكوريتم، كوجىبودن فضاى كليد نسبت به الگوريتم رمز AES و استانداردبودن آن است. فرض كنيد ${ }_{0} \in\{0,1\}^{16}$ $f:\{0,1\}^{16} \rightarrow\{0,1\}^{16} \quad$ يك متن تصادفى و ثابت باشد. تابع

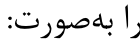

$f(k)=\operatorname{mini} \operatorname{AES}\left(p_{0}, k\right)$

تعريف مى كنيم. اين تابع همه خواص يك تابع تصادفى را دارد. براى ديدن برخى از اين خواص مرجع [4] را ببينيد. در ادامه نقطة شروع تصادفى را براى مقادير مختلف إنى ، كه $0 \leq \log _{2}(t)$ ، تعداد سيس براى هر يك از اين مقادير يك ماتريس هلمن Hبا استفاده تابع تصادفى f و نرمافزار متلب ايجاد كردهايم. درنهايت، بلهراحت نرخ يوشش

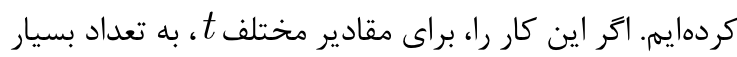
زياد انجام دهيم و ميانتين مقادير بهدستآمده رآ را رسم كنيم، منحنى قرمزرنَ در شكل (זّ) بهدست مى آيد. اين نمودار

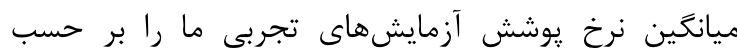
لكاريتم طول زنجيره، يعنى (t)

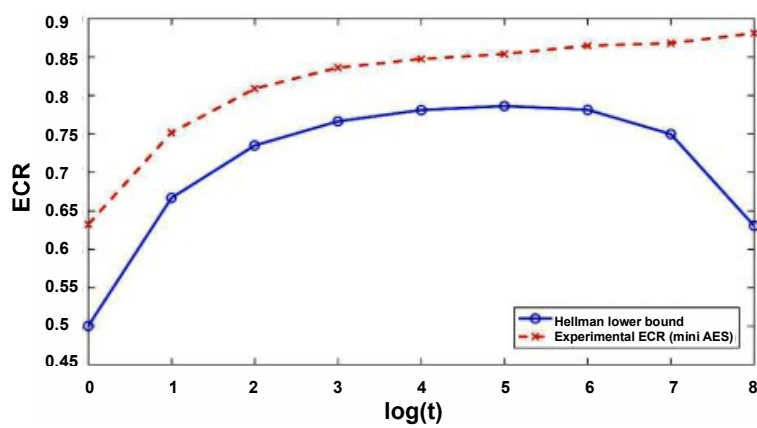

(شكل - ؟): منحنى كران پايين دادهشه توسط هلمن در معادله (T) بر حسب (t)

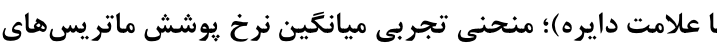

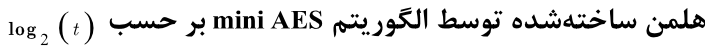
(منحنى خط پاجين با علامت ضرب).

(Figure-3): Given lower bound by Hellman in Equation (3) in logarithmic scale for $N=2^{16}$ and $m=N / t^{2}$ (curve with circle markers); Experimental average of coverage rate of Hellman matrices constructed by mini AES algorithm in logarithmic scale (curve with cross markers).

همانطور كه در شكل (r) مشاهده مى كنيد، منحنى كران ارائهشده توسط هلمن يايينتر از منحنى تجربى قرار

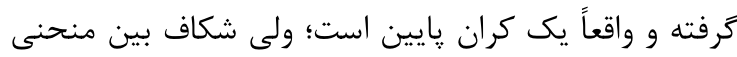


قضيه r-r. فرض كنيد

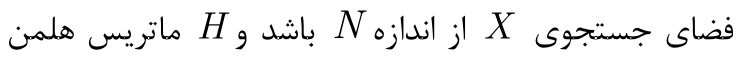

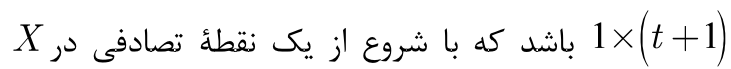
ايجاد شده است. همجنين فرض كنيد

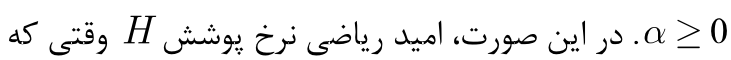

N بهور تقريبى برابر است با:

$\operatorname{ECR}(N, 1, t) \approx \frac{\sqrt{2 \pi}}{\alpha} \int_{0}^{\alpha} \varphi(z) d z$,

كه در آن نرمال استاندارد است. اثبات. فرض كنيد $\rho$ بيشامد تعداد اعضاى زنجيره بدون تكرار

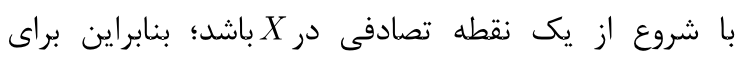

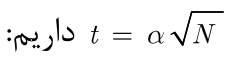

$$
\begin{aligned}
& \operatorname{ECR}(N, 1, t)=\frac{1}{t} \mathbb{E}\left(h_{t}\right)=\frac{1}{t}\left(\sum_{k=0}^{t} \operatorname{Pr}[\rho \geq k]\right) . \\
& \text { حال با استفاده از لهم ا-ـ بهدست مى آوريم: } \\
& \operatorname{ECR}(N, 1, t) \approx \frac{1}{t} \sum_{k=0}^{t} e^{\frac{-k^{2}}{2 N}} . \\
& \text { درنتيجه هنكامى كه CN } \\
& \operatorname{ECR}(N, 1, t) \sim \int_{0}^{1} e^{-\frac{t^{2}}{2 N} x^{2}} \mathrm{~d} x \\
& =\sqrt{2 \pi} \frac{\sqrt{N}}{t} \int_{0}^{\frac{t}{\sqrt{N}}} \varphi(z) \mathrm{d} z \\
& =\sqrt{2 \pi} \frac{1}{\alpha} \int_{0}^{\alpha} \varphi(z) \mathrm{d} z
\end{aligned}
$$

كه در آن

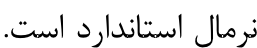

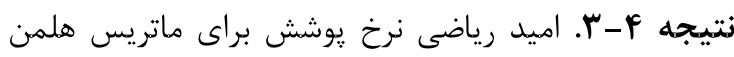

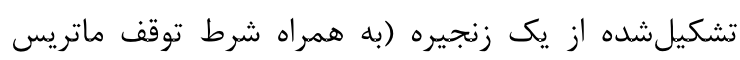

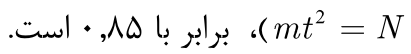

اثبات. توجه كنيد كه در حالت توقف ماتريس،

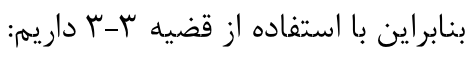

$\lim _{t \rightarrow \infty} \operatorname{ECR}(N, 1, t) \approx \sqrt{2 \pi} \cdot 0.3413=0.85$.

همانكونهكه در اين نتيجه ديديم، يك ماتريس هلمن با يارامترهاى

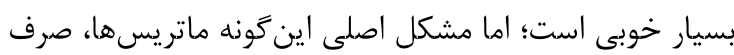

\section{r- اميد رياضى نرخ زيوشش در حالت}

$m=1$

هدف ما در اين بخش محاسبه دقيق اميد رياضى نرخ يوشش

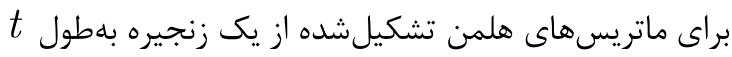

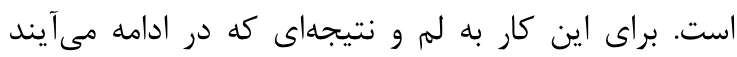

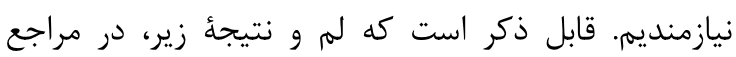
بسيارى از جمله [4, 5, 6 نيز به شكل متفاوتى بررسى شدهاند. لم ا-r. فرض كنيد فضاى جستجوى X از اندازه $\rho=\left|\left\{f^{j}(x): j=0,1,2, \ldots\right\}\right|$

ييشامد تعداد اعضاى زنجيره بدون تكرار با شروع از نقطه

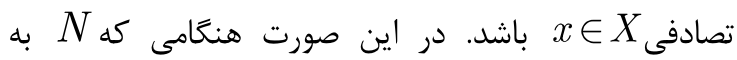
بى $\operatorname{Pr}[\rho \geq t] \approx e^{\frac{t^{2}}{2 N}}$ اثبات. توجه كنيد كه فرآيند ساختن يك زنجيره با استفاده از نقطة شروع تصادفى x را مىتوان به شكل برداشتن مهره

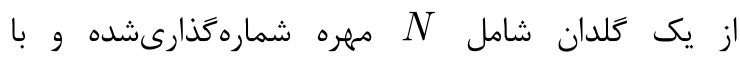
جاى كذارى مدل كرد. بنابراين: عائ $\operatorname{Pr}[\rho \geq t]=\frac{N}{N} \frac{N-1}{N} \frac{N-2}{N} \cdots \frac{N-t+1}{N}$.

مى دانيم هنگامى كه $\operatorname{Pr}[\rho \geq t] \approx \prod_{i=0}^{t-1} e^{-i / N} \approx e^{-t^{2} / 2 N}$

نتيجه r-r. فرض كنيد فضاى جستجو X از اندازه N باشد وم ي بيشامد تعداد اعضاى

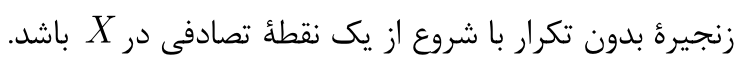
در اين صورت هنگًامى كه ع $\mathbb{E}[\rho] \approx \sqrt{\frac{\pi N}{2}}$.

اثبات. هنگَامى كه م N $\mathbb{E}[\rho]=\sum_{t=0}^{N} \operatorname{Pr}[\rho \geq t] \approx \sum_{t=0}^{N} e^{-t^{2} / 2 N} \approx N \int_{0}^{1} e^{-\frac{N}{2} x^{2}} \mathrm{~d} x$ $=\sqrt{\frac{\pi N}{2}}$.

حال آمادهايم كه با استفاده از نتايج بهدستآمده، اميد رياضى نرخ يوشش براى ماتريسهاى هلمن تشكيلشده از يكى

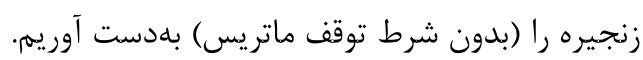


شمارش كرده و با استفاده از نقش تابع f در ستون بعد، اميد رياضى نرخ يوشش (بدون شرط توقف ماتريس) را بهدست

$$
\text { آوريم (بخش ضميمه مرجع [14] را ببينيد). }
$$

حدس r-F. فرض كنيد

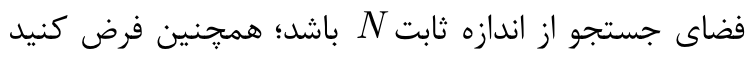
كه H 4 ماتريس هلمن نقطه تصادفى در X ايجاد شده است؛ در اين صورت اميد رياضى نرخ يوشش H بلمطور $\operatorname{ECR}(N, m, t) \approx \frac{N}{m t} s_{t}$ كه در آن براى $\alpha=\sqrt{\frac{m}{2 N}}$

$s_{k} \approx 2 \alpha\left(1-\alpha^{2}\right) \frac{\tanh (\alpha k)}{1+\alpha \tanh (\alpha k)}$.

\section{طرح اثبات. توجه نماييد كه:}

$\mathbb{E}\left(h_{t-1}\right)=\mathbb{E}\left(\left|H_{t-1}\right|\right)=m_{0}+m_{1}+\cdots+m_{t-1}$ كه در آن اعضاى متمايز ستون 1+j است كه در ستونهاى ز و و ما قبل

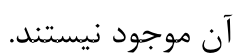

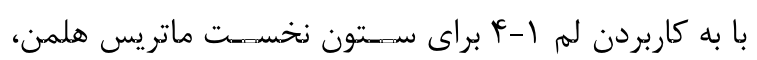

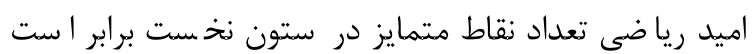

$m_{0}=\mathbb{E}\left(\left|H_{0}\right|\right)=N\left(1-e^{-m / N}\right)$.

توجه كنيد كه اگر آر

باشند، آنكاه توجه كنيد بنابراين تنها درآيههايى مثل $x_{i}$ متعلق به ستون نخست ماتريس هلمن كه متعلق به مجموعه $H_{0}$ هستند، مى توانند

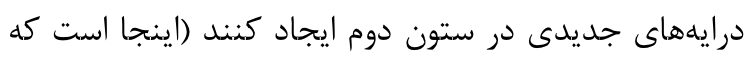

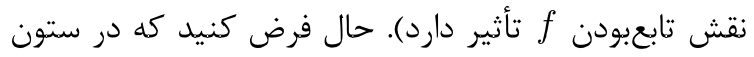
نخست

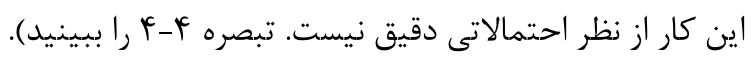
نقش تصادفى تابع f در ايجاد ستون دوم ايجاب مى كند كه به به إنه آن مثل برداشتن

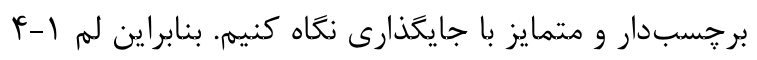
مى كويد، انتظار داريم ستون دوم داشته باشيه. يس تعداد در آيههاى متمايز در ستون دوم كه در ستون نخست نيز نباشند، برابر است با:
زمان بسيار زياد (از مرتبه

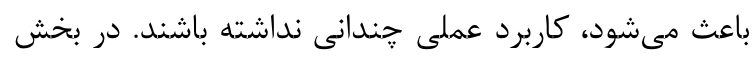

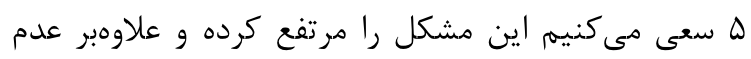

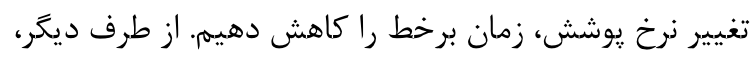

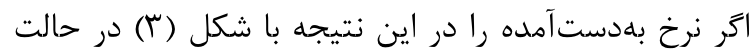
تو $\log (t)=8$

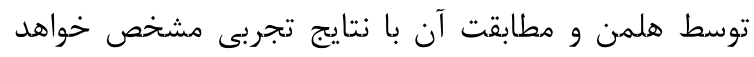

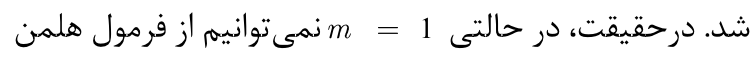

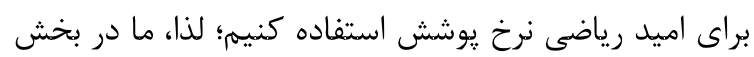

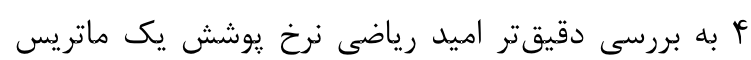
هلمن خواهيه برداخت.

\section{F - محاسبة اميد رياضى نرخ بوشش يك ماتريس هلمن ماتن} هدف ما در اين بخش، محاسبه دقيقتر اميد رياضى نرخ

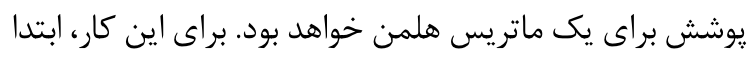

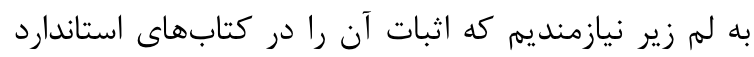
نظريه احتمال مى توان يافت.

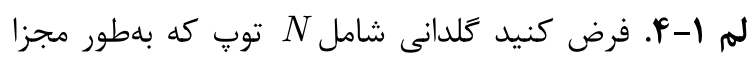
شمارهذذارى شدهاند، داشته باشيم؛ همجنين فرض كنيد

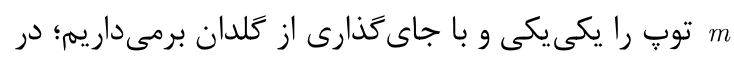

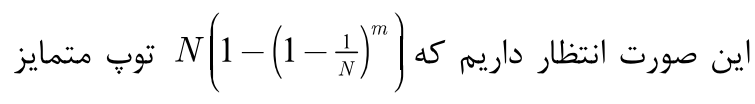

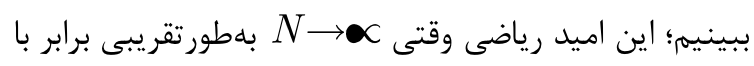
N(1-e 1 است. اميد رياضى يوشش يك تابع تصادفى f به شكل اميد

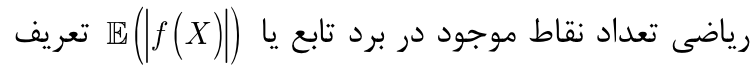
مىشود. توجه كنيد كه، با قراردادن

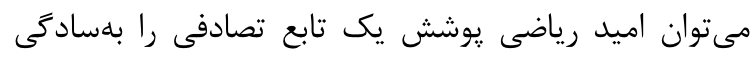

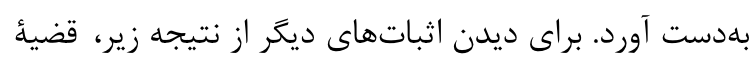
دو در مرجع [4] را ببينيد.

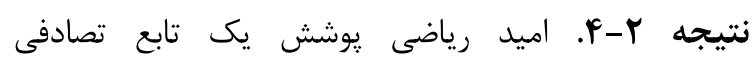
f: $\quad X \rightarrow X$ $\mathbb{E}(|f(X)|) \sim N\left(1-e^{-1}\right)$.

در مدل [7] براى محاسبة اميد رياضى نرخ يوشش،

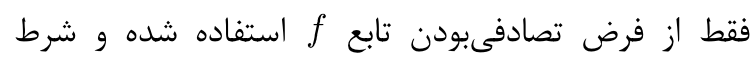

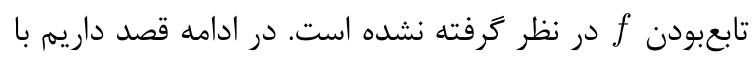

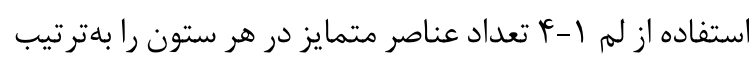


تبصره F F-F. توجه كنيد كه در طرح اثبات حدس r-F فرض كرديم كه تعداد نقاط متمايز در ستون نخست، برابر با اميد

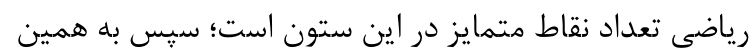

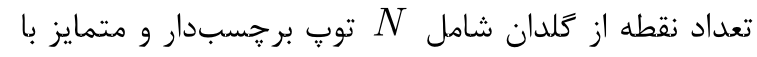
جايحذارى انتخاب كرديم. اين فرض براى ستونهاى بعد نيز

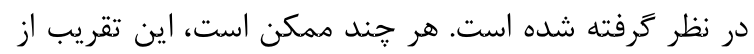
نقطه نظر احتمالاتى دقيق نباشد؛ اما منحنىهاى تجربى در

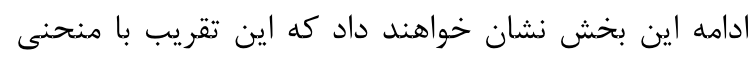
تجربى بلهدستآمده توسط الكوريتم mini AES مطابقت بسيار

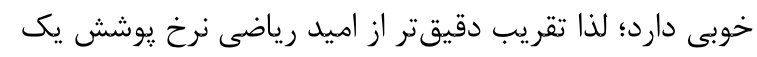
ماتريس هلمن، همجنان مى تواند بهعنوان يكى مسأله باز يثزوهشى مطرح باشد.

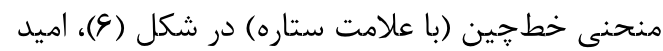

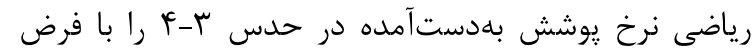
洛 ، $m t^{2}=N=2^{16}$

مشاهده مى كنيد، منحنى خط جين، بسيار نزديك به منحنى

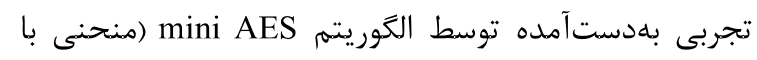

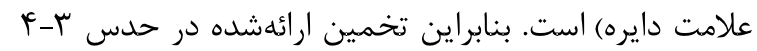
بسيار دقيقتر از تخمين ارائهشده توسط هلمن (منحنى إتى إنى نقطه جين با علامت مربع) است.

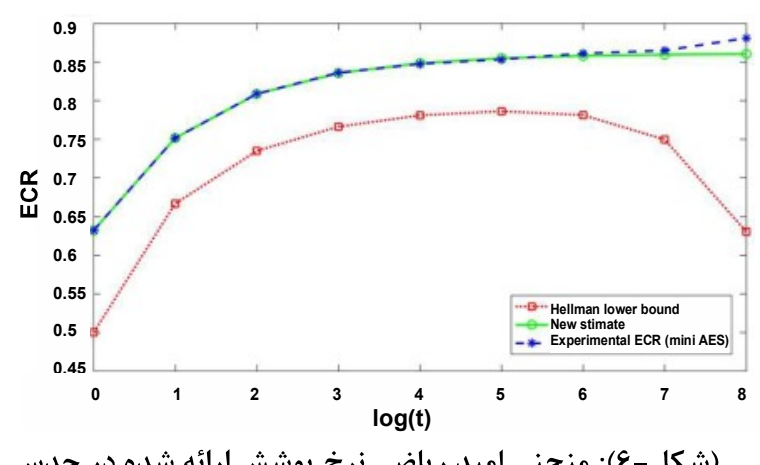

(شكل - 9): منحنى اميد رياضى نرخ يوشش ارائه شده در حدس

r-

علامت ستاره)؛ منحنى نرخ بوشش تجربى با استفاده از الكوريته mini AES هلمن (منحنى نقطه هُين با علامت مربع)

(Figure-6): Expected coverage rate given in Conjecture 4-3 in

logarithmic scale for $N=2^{16}$ (dashed curve with star markers); Experimental coverage rate obtained by using mini AES algorithm (curve with circle markers); Hellman lower coverage (dotted curve with square markers).

نكته قابل توجه در شكل (ع) اين است كه، منحنى

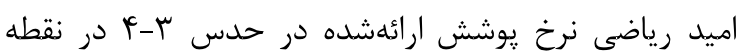
نادقيق است. درحقيقت، همانطور كه در اين شكل $t=\sqrt{N}$ مىبينيد، منحنى تجربى (با علامت دايره) در اين نقطه بالاتر
$m_{1}=\mathbb{E}\left(\left|H_{1} \backslash H_{0}\right|\right)=\left(1-\frac{m_{0}}{N}\right) N\left(1-e^{-\frac{m_{0}}{N}}\right)$.

به همين شكل، آر

$f^{j}\left(x_{i}\right) \in H_{j}$ به ستون (1+1) ام ماتريس هلمن، كه متعلق به مجموعه هستند، مى $H_{j} \backslash H_{j-1}$ 2+2 ايجاد كنند. بنابراين انتظار داريم متمايز در ستون 2+2 داشته باشيم؛ بلهورى كه در ستونهاى ماقبل عضويت ندارند. مثل قبل فرض كنيد كه در در درئه

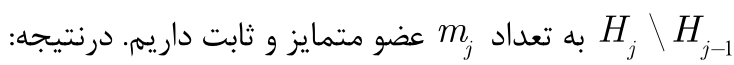
$m_{j+1}=\mathbb{E}\left(\left|H_{j+1} \backslash H_{j}\right|\right)=\left(1-\sum_{i=0}^{k} \frac{m_{i}}{N}\right) N\left(1-e^{-\frac{m_{j}}{N}}\right)$,

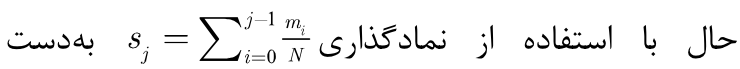
مى آوريم: $1-s_{k+1}=\left(1-s_{1}\right) e^{-s_{k}}, \quad(k \geq 1)$.

فرض كنيد c=e ce در اين صورت با استفاده از شرط اوليه

$s_{0}=0, \quad s_{k+1}=1-c e^{-s_{k}}$.

سرانجام با استفاده از معادله ( ) اميد رياضى نرخ بوشش براى يك ماتريس هلمن به شكل زير است:

$\operatorname{ECR}(N, m, t)=\frac{1}{m t} \mathbb{E}\left(h_{t-1}\right)=\frac{m_{0}+\cdots+m_{t-1}}{m t}=\frac{N}{m t} s_{t}$, براى هر $1 \geq$.

در انتها، براى بهدستآوردن يك شكل بسته براى فرمول

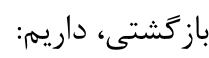
$\frac{\mathrm{d} s_{k}}{\mathrm{~d} k} \approx s_{k+1}-s_{k}=\left(1-s_{k}\right)-e^{-\left(s_{k}+\frac{m}{N}\right)}$

لذا با استفاده از تقريب بسط تيلور تابع نمايى $e^{x} \approx 1+x+\frac{1}{2} x^{2}$

$$
\frac{\mathrm{d} s_{k}}{\mathrm{~d} k} \sim \frac{m}{N}-\frac{1}{2}\left(s_{k}+\frac{m}{N}\right)^{2}, \quad s_{0}=0 .
$$

با حل اين معادله ديفرانسيل داريم:

$k \approx \alpha^{-1}\left(\tanh ^{-1}\left(\frac{1}{2} \alpha^{-1} s_{k}+\alpha\right)-\tanh ^{-1}(\alpha)\right)$.

كه در آن $\alpha=\sqrt{\frac{m}{2 N}}$ بdدست مى آيد. 
با استفاده از معادله (Y)، احتمال موفقيت روش ما براى ماتريس بلهور تقريبى برابر است با: $1-e^{-r \sqrt{\frac{\pi}{2 N}}}$

منحنى اين فرمول بر حسب (r) در شكل (V) با منحنى خط إجين (با علامت دايره) رسم شده

براى مقايسه اين منحنى با دادههاى تجربى، مشابه با

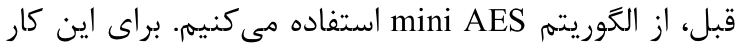
تعداد r،

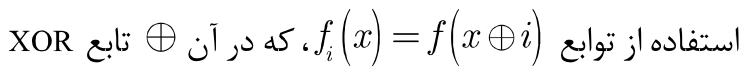
است، تشكيل مىدهيم؛ سيس تعداد نقاط متمايز در كل

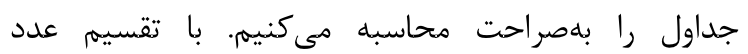
بهدستآمده بر

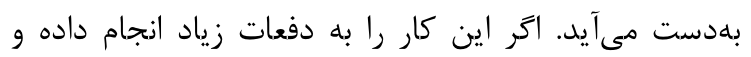

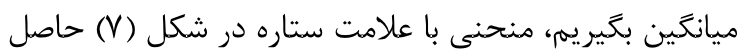

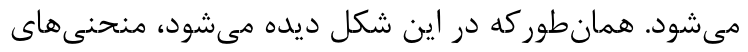
نظرى و تجربى مطابقت بسيار خوبى با يكديكر دارند.

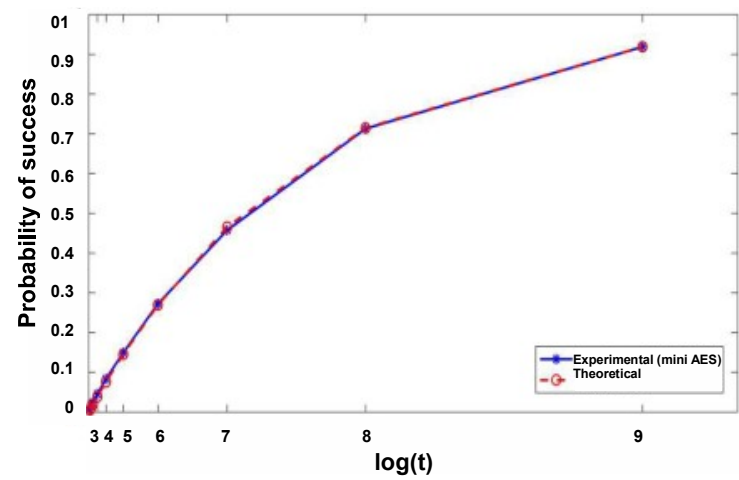

(شكل - V): منحنى اميد رياضى نرخ بوشش r ماتريس به روش ييشنههادى بر حسب (r) دايره) در مقايسه با منحنى نرخ بوشش

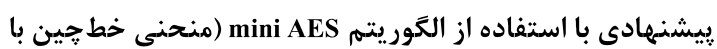
علامت ستاره).

(Figure-7): Theoretical expected coverage rate of $r$ matrix with presented method in logarithmic scale (curve with circle markers); Experimental coverage rate of $r$ matrix with presented method in logarithmic scale using mini AES algorithm (dashed curve with star markers).

يكى از مشكلاتى كه باعث مىشود r ماتريس تشكيلشده به روش بيشنهادى از نظر عملى ناكارآهد باشند،

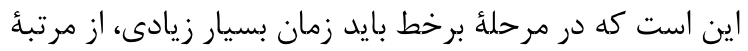

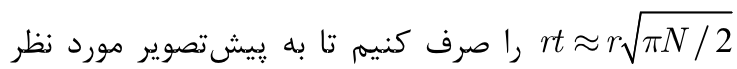

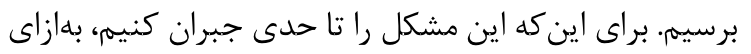

از منحنى خط هين (با علامت ستاره) قرار گرفته است. البته

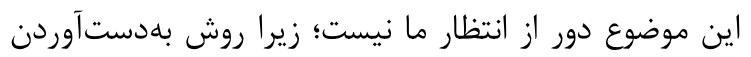

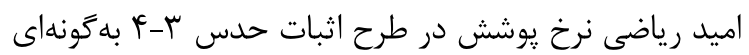

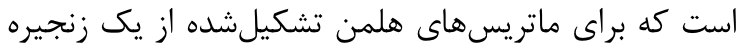

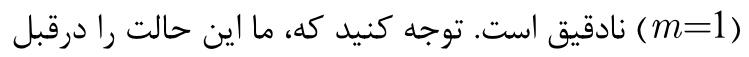

$$
\text { در بخش سوم بررسى كردهايم. }
$$

\section{ه- روشى جديد براى توليد ماتريس \\ هلمن}

همانطور كه در بخش جههارم مشاهده كرديد، اميد رياضى نرخ يوشش يك ماتريس هلمن، با شرط توقف ماتريس، يك تابع صعودى بر اساس t است. بنابراين در حالت باست t $=\sqrt{N}$ در بخش سوم، اين اميد رياضى را بهدقت محاسبه كرديم و

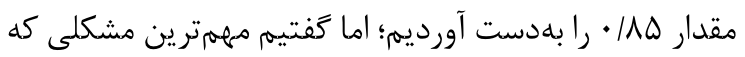

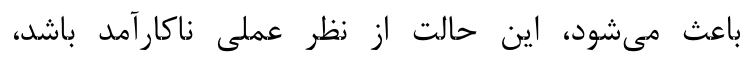
مدتزمانى (از مرتبه صرف شود تا به يِشتصوير نقطئ دادهشده برسيم. در اين بخش روشى جديد براى توليد يك ماتريس هلمن بيشنئهاد مى كنيم كه داراى بيشترين اميد رياضى نرخ بوشش درئ است.

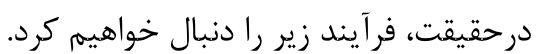
فرض كنيد تابع تصادفى f داده شده باشد، هدف ما داد در درد اين بخش ساختن r ماتريس است كه در هر يك از آنها از

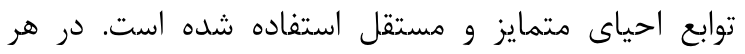

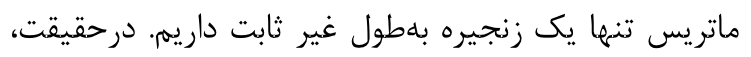

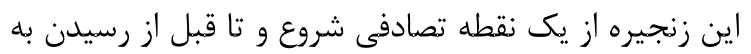

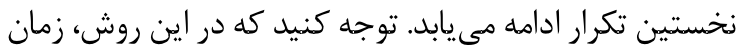

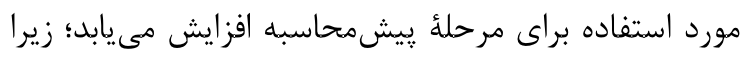
در طى ساخت يكى زنجيره، بايد بتوانيم دور را تشخيص داده و قبل از رسيدن به نخستين تكرار، ساخت زنجيره را رايايان

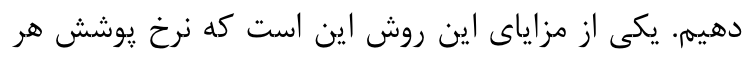

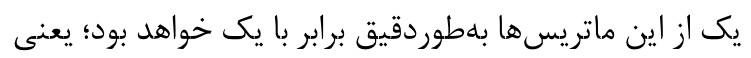
هيج نقطة تكرارى در اين كونه ماتريسها وجود ندارد. از طرف درف

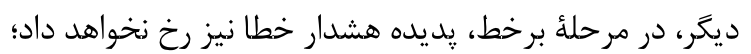

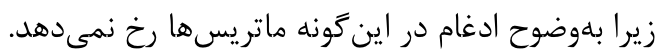

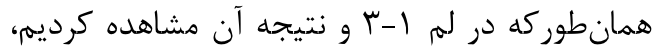
اميد رياضى تعداد اعضاى يك زنجيرء تصادفى برابر با فيا است. حال، جون 1 است 
(1) حافظه نسبت به روش هلمن تغييرى نكرده است؛ اما زمان

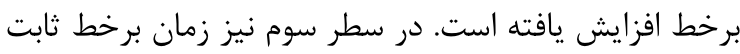
مانده است؛ اما حافظه افزايش يافته است. مثال. براى مقايسُٔ تجربى احتمال موفقيت، حافظه و وافتو زمان برخط روش هلمن با روش ارائهشده در اين بخش، مشابـ احتيه

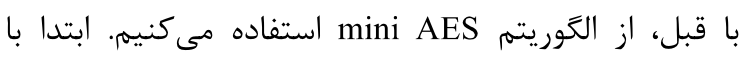
استفاده از روش هلمن و شرط توقف ماتريس

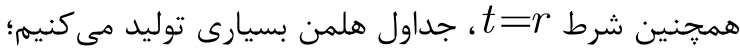

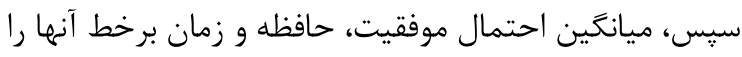
بهدقّت بر حسب (t) نمودارهايى را نيز براى روش ارائهشده و با تعداد جداول دران

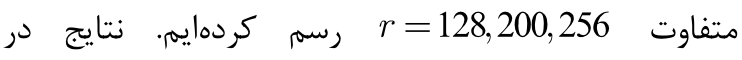
شكلهاى (1،، 9، · ( ) ارائه شدهاند.

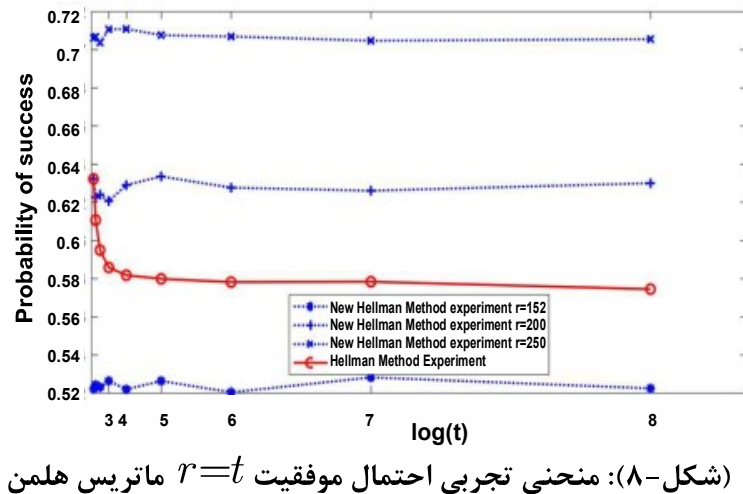

(شكل-^): منحنى تجربى احتمال موفقيت با شرط توقف ماتريس منحنى هاى احتمال موفقيت روش ارائهشده بلازاى (منحنى نقطه جين با علامت ستاره)، 200 (م)

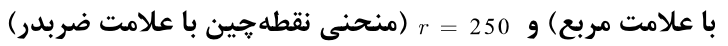

$$
\text { بر حسب (t) }
$$

(Figure-8): Experimental probability of success of $r=t$ Hellman matrix with matrix stopping rule condition

$N=m t^{2}$ (curve with circle markers); Experimental probability of success of $r$ table with presented method for $r=150$ (dotted curve with circle markers), $r=200$ (dotted curve with square markers) and $r=250$ (dotted curve with cross markers) in logarithmic scale.

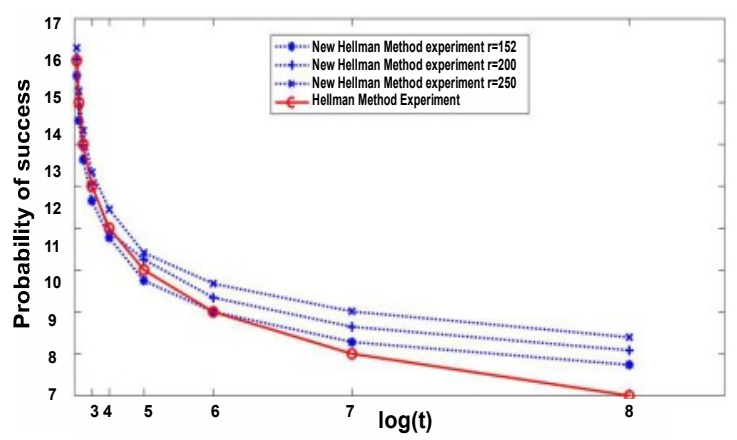

(شكل -9): منحنى تجربى واحد حافظه مورد نياز براى ذخيره N $N=m t^{2}$ منحنى $r=t$
يك t' مناسب (بر حسب زمان مورد نياز كاربر در مرحلة برخط

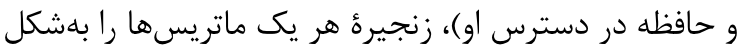
زير به زيرزنجيرههايى با طول 't تقسيهم مى كنيم:

$$
\begin{gathered}
x_{1,0} \rightarrow x_{1,1} \rightarrow x_{1,2} \quad \rightarrow \cdots \rightarrow x_{1, t^{\prime}} \rightarrow \\
\rightarrow x_{2,0} \rightarrow x_{2,1} \rightarrow x_{2,2} \rightarrow \cdots \rightarrow x_{2, t^{\prime}} \rightarrow \\
\vdots \\
\rightarrow x_{m^{\prime}, 0} \rightarrow x_{m^{\prime}, 1} \rightarrow x_{m^{\prime}, 2} \rightarrow \cdots \rightarrow x_{m^{\prime}, t^{\prime}}
\end{gathered}
$$

كه در آن و 1 $1 \leq i \leq m^{\prime} \quad$ و $f\left(x_{i, j}\right)=x_{i, j+1}$

$$
2 \leq i \leq m^{\prime} \text {. } 2 \text { براى } f\left(x_{i, t^{\prime}}\right)=x_{i+1,0}
$$

توجه كنيد كه با اين كار نرخ يوشش و درنتيجه احتمال موفقيت تفاوتى با قبل نخواهد داشت؛ ولى حافي حافظه

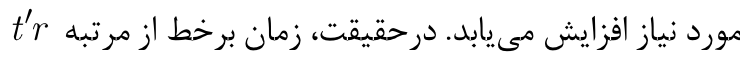

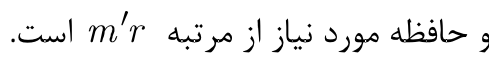
مثال. فرض كنيد

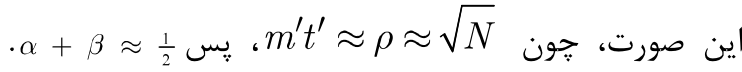
درنتيجه، زمان برخط از مرتبه 泟 $t^{\prime} r \approx N^{\beta+\gamma}$

$$
\text { موفقيت بهطورتقريبى برابر است با: }
$$

$1-\exp \left(-\left(N^{\gamma-\frac{1}{2}}\right) \sqrt{\frac{\pi}{2}}\right)$.

در جدول (1)، مرتبه زمان برخط، حافظه و احتمال موفقيت براى קند نمونه هحاسبه شده است. همانطوركه

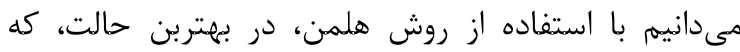

\begin{tabular}{|c|c|c|c|c|c|}
\hline \multicolumn{6}{|r|}{. } \\
\hline$\alpha$ & $\beta$ & $\gamma$ & زمان برخط & حافظه & احتمال موفقيت \\
\hline$\frac{1}{4}$ & $\frac{1}{4}$ & $\frac{1}{2}$ & $N^{3 / 4}$ & $N^{3 / 4}$ & 0.714 \\
\hline$\frac{1}{3}$ & $\frac{1}{6}$ & $\frac{1}{2}$ & $N^{5 / 6}$ & $N^{2 / 3}$ & 0.714 \\
\hline$\frac{1}{6}$ & $\frac{1}{3}$ & $\frac{1}{2}$ & $N^{2 / 3}$ & $N^{5 / 6}$ & 0.714 \\
\hline
\end{tabular}
و $t r \approx N^{2 / 3}$ حالته حافظه از مرتبه

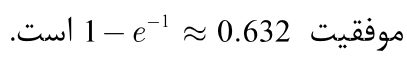

(جدول -(): جند نمونه از هار امترها براى روش پِيشنهادى

(Table-1): some parameters for presented method

با توجه به نتايج جدول (1) مشاهده مىشود كه اتر خه

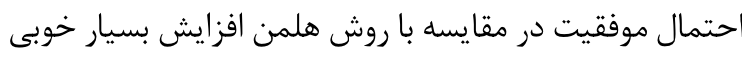

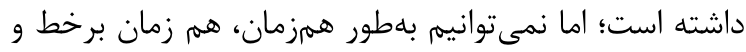

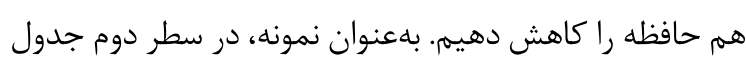


اصلى دادهشه توسط خود ارائه داده است. تحليلهاى ساير

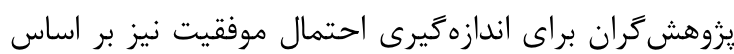
همين كران پايين بوده است. در اين مقاله، ابتدا نشان داديم كه يك شكاف بين كران קايين دادهشده توسط هلمن و مقادير تجربي بهدستآمده توسط الكَوريتم رمز mini AES وجود دارد. اين شكاف بين نمودار تجربى و نظرى در جايى كه هر تهر تهر ماتريس هلمن تنها شامل يك زنجيره است، بيشتر از جاهاى ديكر بود؛ لذا به بررسى ماتريسهاى هلمنى يرداختيم كه نهان

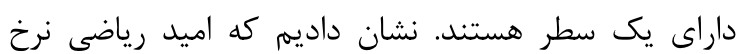
يوشش اينَّونه ماتريسهاى هلمن (با شرط توقف ماتريس)

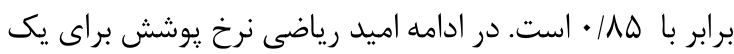
ماتريس هلمن را بلهطور دقيقترى محاسبه كرديم. نتايج بلهدست آمده با مثال هاى عملى مقايسه شدند و نشان داده شد دان كه فرمول بيشنهادى ما براى اميد رياضى نرخ يوشش، بسيار دقيقتر از كران بايين دادهشه توسط هلمن است. درنهايت، ازآنجايى كه احتمال موفقيت در مصالحئ حافظهزمان دارين إداى اهميت بسيارى در كارهاى عملى است، روشى براى ساختن

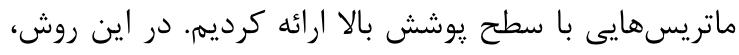

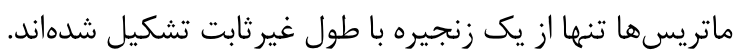
درحقيقت هر زنجيره تا قبل از رسيدن به نخستين تكرار ادامه

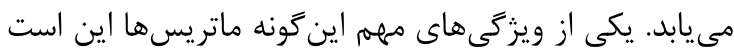

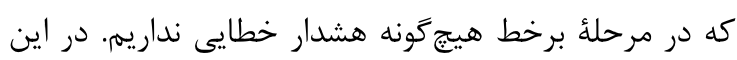
بخش سعى كرديم علاوهبر اين كه ويزَّى هاى خوب اينَّونه

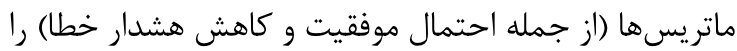

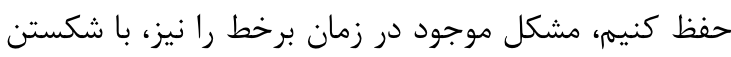

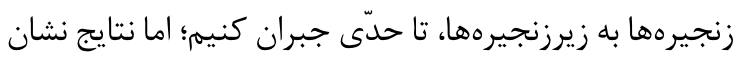
دادند كه با اين كار واحد حافظهٔ مورد نظر افزايش مى يابد.

\section{7- References}

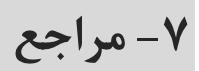

[1] E. Barkan, E. Biham and A. Shamir, "Rigorous bounds on cryptanalytic time/memory tradeoffs", in Advances in Cryptology: Proceedings of Crypto, LNCS, 2006, 4117, pp. 1-21.

[2] J. Borst, "Block Ciphers: Design, Analysis and Side-Channel Analysis", PhD thesis, Katholieke Universiteit Leuven, 2001.

[3] D.E. Denning, Cryptography and data security, Addison-Wesley, 1982.

[4] P. Flajolet, and A. Odlyzko, "Random mapping statistics", Advances in Cryptology, Proceedings of Eurocrypt'89, LNCS, 1990, 434, pp. 329-354.
با علامت دايره) و منحنى تجربى واحد حافظه مورد نياز براى

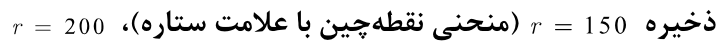

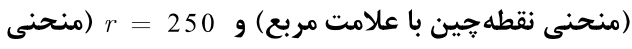

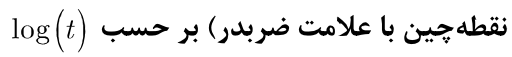

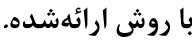

(Figure-9): Experimental memory requirements of $r=t$

Hellman matrix with matrix stopping rule condition $N=m t^{2}$ (curve with circle markers); Experimental memory requirements of $r$ table with presented method for $r=150$ (dotted curve with circle markers), $r=200$ (dotted curve with square markers) and $r=250$ (dotted curve with cross markers) in logarithmic scale.

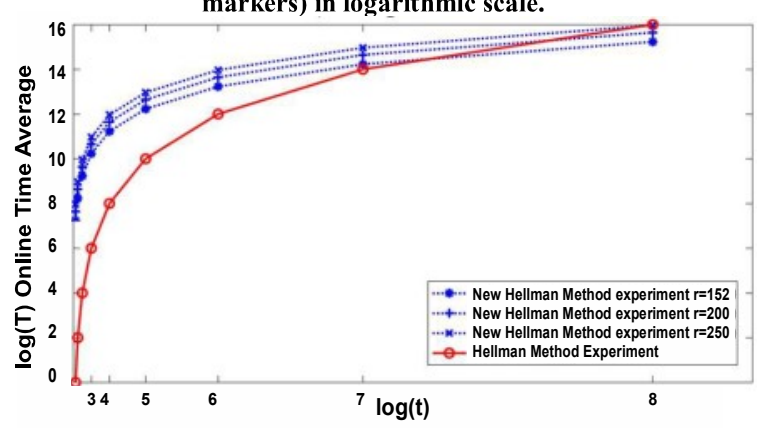

(شكل-••): منحنى تجربى زمان برخط $=t r=t$ ماتريس هلمن با

شرط توقف ماتريس

منحنى تجربى زمان برخط 150 r=

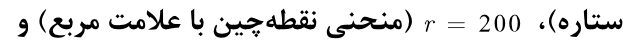

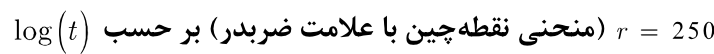

با روش ارائهشده.

(Figure-10): Experimental online time of $r=t$ Hellman

matrix with matrix stopping rule condition $N=m t^{2}$ (curve with circle markers); Experimental online time of $r$ table with presented method for $r=150$ (dotted curve with circle markers), $r=200$ (dotted curve with square markers) and $r=250$ (dotted curve with cross markers) in logarithmic scale.

همانطوركه در اين شكلها مشاهده مى كنيد، براى

,r=200

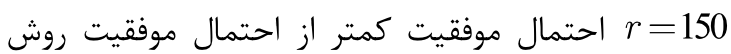

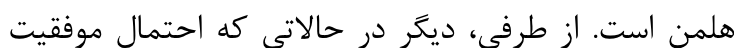
بهبود يافته، يا تعداد واحد حافظه بيشتر شده است و يا زمان برخط. بنابراين نتيجه مى تيريم، با ثابتنگهداشتن زمان

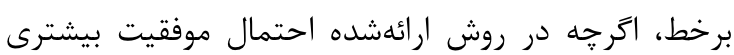
نسبت به روش هلمن داريم و در مرحله برخط نيز با هشدار خطاى بسيار كمترى مواجه خواهيم بود، اما مجبور به استفاده از واحد حافظه بيشترى نسبت به روش هلمن هستيم.

\section{9- نتيجه}

مصالحة حافظهزمان يك الكوريتم احتمالاتى براى وارونكردن

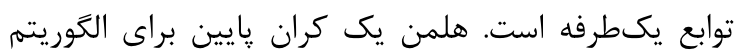




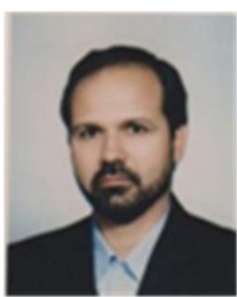

عبدالرسول ميرقدرى، در رال

هاצr| مدرى كارشناسى در رشتهُ آمار

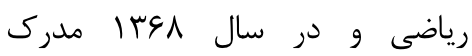
كارشناسى ارشد خود را در رشته آمار نظرى از دانشعاه شيراز و همجنين مدرك دكتراى خود را در رشتئ آمار

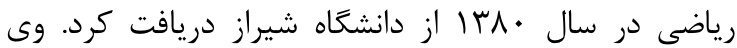

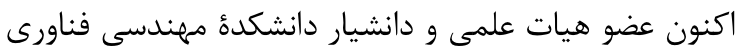
اطلاعات و ارتباطات دانشخاه جامع امام حسين (ع) است. زمينههاى يزوهشى مورد علاقة ايشان فرآيندهاى تصادفى، نهان نظارى، رمزنگارى و تحليل الكوريتمهاى رمز است. نشانى رايانامة ايشان عبارت است ازئ amrghdri@ihu.ac.ir

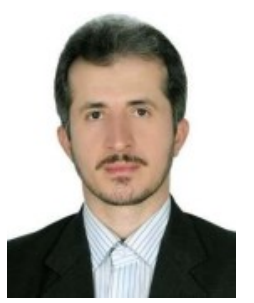

محمد عبداللهى ازَّمى، تحصيلات دانشخاهى خود را در مقاطع كارشناسى،

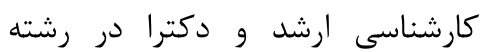
مهندسى كامييوتر-نرمافزار بلهترتيب در

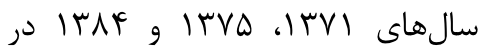
دانشكده مهندسى كامييوتر، دانشگاه صنعتى شريف به پايان رسانده است. زمينههاى يزوهشى مورد

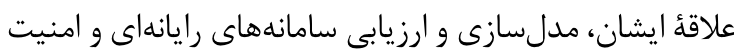

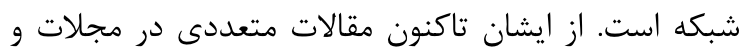

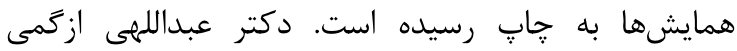

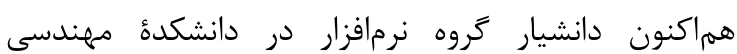
كاميّيوتر، دانشگاه علم و صنعت ايران است.

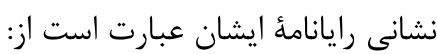

azgomi@iust.ac.ir

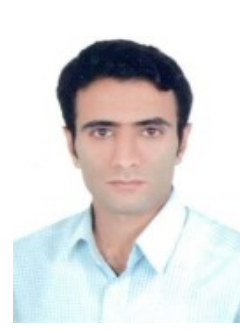

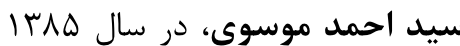
مدرك كارشناسى خود را در رشته رياضى محض از مانشعاه كاشان

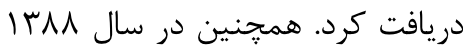
مدرك كارشناسى ارشد و در در سال سوسا مدرك دكتراى خود را در رشته

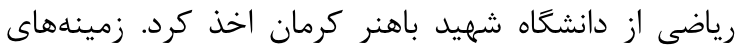
يزوهشى مورد علاقهٔ ايشان نظريه اطلاعات كوانتومى، نظرية ماتريسها، رمزنگارى و تحليل الكوريتمهاى رمز است. نشانى رايانامةٔ ايشان عبارت است ازترئ s.a.mousavi@math.uk.ac.ir
[5] P. Flajolet, and R. Sedgewick, An introduction to analysis of algorithms, Addison-Wesley, 2013.

[6] B. Harris, "Probability distributions related to random mappings", The Annals of Mathematical Statistics, pp. 1045-1062, 1960.

[7] M. Hellman, "A cryptanalytic time-memory tradeoff', IEEE Transactions on Information Theory IT, vol. 26, pp. 401-406, 1980.

[8] J. Hong, and S. Moon, "A comparison of cryptanalytic tradeoff algorithms", Journal of cryptology, vol. 26 (4), pp. 559-637, 2013.

[9] J. Hong and B.I. Kim, "Performance comparison of cryptanalytic time memory data tradeoff methods", Bull. Korean Math. Soc., vol. 53(5), pp. 14391446, 2016.

[10] V. Kolchin, "Random mapp-ings", Translations series in mathematics and engineering, Optimization Software, Inc., Publications Division, 1986.

[11] K. Kusuda, and T. Matsumoto, "Optimization of time-memory trade-off cryptanalysis and is application to DES", FEAL-32, and Skipjack, E79A, pp. 35-48, 1996.

[12] G. W. Lee, and J. Hong, "Comparison of perfect table cryptanalytic tradeoff algorithms", Designs, Codes and Cryptography, pp. 473-523, 2016.

[13] R.C. Phan, "Mini advanced encryption standard (mini-AES): a testbed for cryptanalysis students", Cryptologia, vol. 26(4), pp. 283-306, 2002.

[14] $\mathrm{Ph}$. Oechslin, "Making a faster cryptanaly-tic time-memory trade-off", Annual International Cryptology Conference, Springer Berlin Heidelberg, 2003.

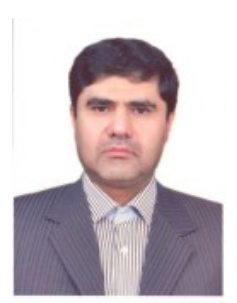

ناصرحسين غروى، تحصيلات دانشگاهى خود در مقطع كارشناسى در رشته مهندسى مخابرات در سال ر

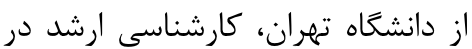

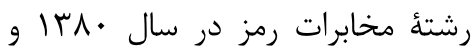

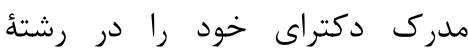

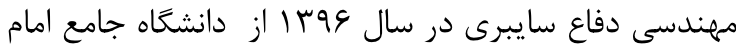

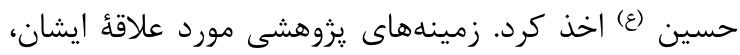

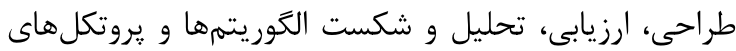

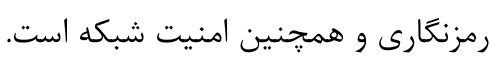
نشانى رايانامةٔ ايشان عبارت است ازمين امنيت ستبله

hgharavi@ihu.ac.ir 